\title{
Features of Non-Verbal Communication of Children with Intellectual Disabilities and Differences from their Normatively Developing Peers
}

\author{
Oksana V. Zashchirinskaia*
}

\author{
Department of Pedagogics and Pedagogical Psychology, Saint Petersburg State University, Saint \\ Petersburg, Russian Federation
}

\begin{abstract}
Objective: The study aimed to study the specific features of non-verbal communication in children with intellectual disabilities in the dynamics of psychological impact.

Background: In the 21st century, in terms of diagnostics and the implementation of psychological influences, the problem of identifying the features of the communication skills of children with intellectual disabilities becomes very significant and urgent. At present, intellectual disabilities are understood as a heterogeneous group of intellectual impairments, different in clinical manifestations, but based on the criterion of a decrease in cognitive development. A comparatively large number of works are devoted to the study of the features of the communication skills of children with intellectual disabilities. However, the research on their non-verbal communication skills is rather small.
\end{abstract}

Method: The experimental research was conducted in three stages - first, the initial level of development of the abilities of recognition, naming and use of various communicative, modal and descriptive-pictorial gestures was measured.

Results: After that, for ten lessons with children, the program "Lessons of non-verbal communication at school" was carried out, after which abilities were tested repeatedly. Parents and teachers were also interviewed twice.

Conclusion: The study was carried out based on educational institutions outside school hours. The study involved 128 children from 6 schools in St. Petersburg. Non-verbal communication of children with mild mental retardation in comparison with normatively developing peers and with mixed specific psychological disorders is characterised by a lower level of development of cognitive, emotional-personal and behavioural components. Moreover, the most pronounced is the underdevelopment of the cognitive component, which is associated with the peculiarities of the impairment of intelligence. The study also showed that the emotional-personal and behavioural components are at a more preserved level of development in children with intellectual disabilities, which can be interpreted as the compensatory ability of the child's psyche.

Keywords: Children with special educational needs, students with intellectual disabilities, school curriculum, inclusive education, communication between students.

\section{INTRODUCTION}

Communication is the most important factor in the formation of a personality, one of the main types of human activity, aimed at knowing and evaluating oneself through interaction with other people. As L.S. Vygotsky and other researchers believed, the development of the human psyche occurs only in joint activities and communication [1-4]. At the same time, communication includes not only the ability of a person to use natural language but also the use of all possible means of expression by a person of his internal, psychological states, images, thoughts and feelings in order to communicate them to other people. Thus, the communication process includes the use of natural, artificial languages, as well as such means of expressing human psychology and influencing other people, which are not associated with natural and artificial languages. A comparatively large number of

*Address correspondence to this author at the Saint Petersburg State University, Saint Petersburg, Russian Federation; Tel: +7812 36366 33; E-mail: zashchirinskaia5112@ubogazici.in works are devoted to the study of the features of the communication skills of children with intellectual disabilities [5-8]. For children with complex disabilities, communication takes on special importance; however, $20-25 \%$ of children never master verbal speech, although they can understand simple instructions and learn the meaning of some gestures, which allow them to compensate to some extent for speech deficiencies $[9,10]$. Thus, the use of non-verbal communication for many children remains the only option for the implementation of communication, and, ultimately, development. Consider some of the methods of nonverbal communication offered for working with children with severe speech impairments that remain with the impaired musculoskeletal system; combined impairment of intelligence and early childhood autism, et al. [11-13].

As a result of numerous modern psychological and medical studies, it has been revealed that there are a number of contradictions between:

theory and practice of medical psychology. This contradiction is expressed in the fact that in the 
implementation of programs of psychological impact, the emphasis is shifted to the development of social behaviour, but conceptual approaches to the study of the psyche as a poly structural and multifunctional phenomenon are not sufficiently considered;

- $\quad$ the problem of non-verbal communication of children with intellectual disabilities and methods of psychological influence, which implies an emphasis on the formation of specific communication skills without optimal use of the compensatory potential of non-verbal means of communication with others, aimed at the development of non-verbal communication of primary school children with intellectual disabilities during the period of adaptation to school;

- the significance of this problem and the insufficient number of methods, technologies of psychological influence to improve their communicative resources and potential in socialisation in working with children of primary school age with intellectual disabilities.

All of the above made it possible to formulate the research problem - to identify the features of nonverbal communication in children with intellectual disabilities and to test the program of psychological influence to increase the effectiveness of psychological assistance to such children in the process of schooling.

\section{MATERIALS AND METHODS}

Students of the first grades of educational institutions of the city of St. Petersburg were the sample of the study. In total, the study involved 128 children - first-grade students (average age - 7.4 years; 47 girls, 81 boys). As a result, the study sample consisted of first-grade students of the following schools in St. Petersburg: state budgetary educational institution School No. 7 of the Krasnoselsky district of St. Petersburg, state budgetary educational institution boarding school No. 22 of the Nevsky district of St. Petersburg, state budgetary educational institution School No. 131 of the Krasnoselsky district of St. Petersburg, state budgetary educational institution school No. 502 of the Kirovsky district of St. Petersburg, state budgetary educational institution general educational institution school No. 663 of the Moskovsky district of St. Petersburg, the state budgetary educational institution, secondary school No. 237 of the Krasnoselsky district of St. Petersburg.
Taking into account modern trends in the development of clinical psychology, the following theories, principles and approaches have been identified:

- $\quad$ the principle of the unity of consciousness and activity, which determines the practical activity of a person as a reflection of the functions of his psyche;

- $\quad$ the systematic approach, which made it possible to consider mental retardation as an integral element, a special state of the psyche, characterised by underdevelopment of the intellect [14];

- the dynamic functional approach to the personality structure of K.K. Platonov;

- the structural-dynamic approach that allows considering the three-component structure of the features of non-verbal communication, including cognitive, emotional-personal and behavioural components [15];

- $\quad$ the evolutionary approach to understanding the relationship between non-verbal and verbal communication in the process of ontogenesis;

- $\quad$ the principle of determinism, which establishes the relationship between behaviour and communication with internal psychological phenomena in the cognitive, emotional-personal and behavioural spheres;

the theory of compensation [3] contributing to the understanding of the development of the potential of children with mental retardation in the process of targeted psychological impact.

During the dissertation research, the following methods were used: clinical and psychological method, experimental psychological method, as well as the method of expert assessments. To process and analyse the data, the computer program "Statistical package for social sciences" (IBM SPSS Statistics) version 22 was used. Various methods of mathematical and statistical processing of indicators of communication development were used: Student's ttest, factor and variance analyses.

\section{RESULTS}

Based on the obtained factor assessments, groups of children with intellectual disabilities and the 
Table 1: Differences between Groups of Children with Intellectual Disabilities and the Normative Intellectual Level in Terms of the Ability to Recognise and Understand Gestures before Psychological Impact

\begin{tabular}{|c|c|c|c|}
\hline Comparison parameter & $\begin{array}{c}\text { Average value, group } 1 \\
\text { (children with intellectual } \\
\text { disabilities) } \\
\text { (M士sd) }\end{array}$ & 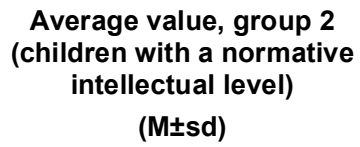 & $\begin{array}{l}\text { Significance level of } \\
\text { differences }(p)\end{array}$ \\
\hline Cognitive component & $15.53 \pm 12.87^{*}$ & $2.11 \pm 1.80^{*}$ & $<0.01$ \\
\hline Emotional-personal component & $3.48 \pm 0.16^{*}$ & $2.29 \pm 0.82^{*}$ & $<0.01$ \\
\hline Behavioural component & $3.8 \pm 0.13^{*}$ & $3.37 \pm 1.22^{*}$ & $>0.05$ \\
\hline
\end{tabular}

Note: * - statistically significant differences were found for children from this group in comparison with the assessments for this parameter before psychological impact.

normative level of intelligence for a number of measured parameters were compared. The group of children with intellectual disabilities included children with diagnoses of mental retardation (MD) and mixed specific disorder of psychological development (MSDD). The assessments of these parameters were compared before and after the psychological impact. The parametric Student's t-test was used for comparison. The comparison was conducted in order to search for general and specific characteristics of the surveyed groups, to assess the differences in the effectiveness of psychological influence for different groups of children. In the course of study of the ability to recognise and understand gestures, the groups were compared according to factor assessments before the start of psychological influence. The comparison results are presented in Table 1. It was found that children with intellectual disabilities spend significantly more time on recognising and identifying stimulus gestures than children with a normative level of intelligence. On a qualitative level, the responses of children with intellectual disabilities correspond to the assessment "no response, inadequate interpretation of people's actions, a justification for the wrong naming of a gesture". These children are characterised by a specific understanding of the gesture, difficulties in correlating the gesture and social situations. It was found that groups of children differ in the cognitive and emotional-personal components of non-verbal communication; no significant differences in the behavioural component were found.

When comparing the groups after psychological exposure, significant differences were found in comparison with the assessments before psychological exposure in all parameters. Children with intellectual disabilities have become much better at recognising various gestures and have learned to relate them to social situations. Differences arose between the groups in the cognitive, emotional-personal components and in the behavioural component. Corresponding differences were found in the group of children with a normative level of intellectual development. The data obtained are presented in Table 2.

The data obtained indicate that the developed and implemented program is highly effective in correcting the characteristics of non-verbal communication in children with intellectual disabilities. This is also confirmed by the high possibilities of correction in this group of children. The program was found to be effective both for these children and for peers with a normative level of intelligence.

In the course of the study of the ability to recognise and understand gestures in different situations, the groups were compared according to factor

Table 2: Differences between Groups of Children with Intellectual Disabilities and the Normative Intellectual Level in Terms of the Ability to Recognise and Understand Gestures after Psychological Impact

\begin{tabular}{|c|c|c|c|}
\hline Comparison parameter & 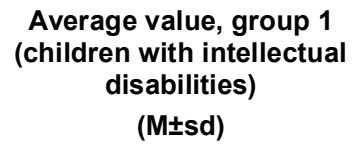 & 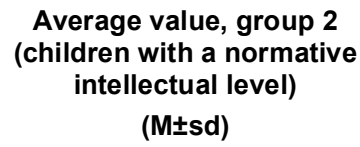 & $\begin{array}{c}\text { Significance level of } \\
\text { differences (p) }\end{array}$ \\
\hline Cognitive component & $7.61 \pm 10.87^{*}$ & $0.49 \pm 0.72^{*}$ & $<0.01$ \\
\hline Emotional-personal component & $1.5 \pm 0.08^{*}$ & $0.54 \pm 0.50^{*}$ & $<0.01$ \\
\hline Behavioural component & $1.59 \pm 0.07^{*}$ & $0.58 \pm 0.59^{*}$ & $<0.01$ \\
\hline
\end{tabular}

Note: * - statistically significant differences were found for children from this group in comparison with the assessments for this parameter before psychological impact. 
Table 3: Differences between Groups of Normatively Developing Children and Children with Intellectual Disabilities in Terms of the Ability to Recognise and Understand Gestures in Situations before Psychological Impact

\begin{tabular}{|c|c|c|c|}
\hline Comparison parameter & 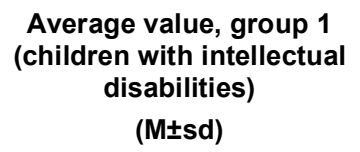 & 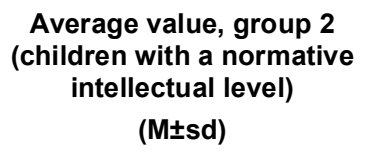 & $\begin{array}{l}\text { Significance level of } \\
\text { differences }(p)\end{array}$ \\
\hline Emotional-personal component & $0.97 \pm 10.87$ & $2.94 \pm 0.84$ & $<0.01$ \\
\hline Cognitive component & $3.32 \pm 0.08$ & $2.17 \pm 1.87$ & $<0.01$ \\
\hline Understanding of spatial relations & $0.29 \pm 0.06$ & $1.18 \pm 0.94$ & $<0.01$ \\
\hline Behavioural component & $0.94 \pm 0.05$ & $2.01 \pm 1.24$ & $<0.01$ \\
\hline
\end{tabular}

assessments before psychological impact. The comparison results are presented in Table 3 . It was found that the assessments of children with intellectual disabilities in recognition of gestures in various situations are significantly lower than those of children with a standard level of intelligence. Statistically significant differences were found for all studied components.

When answering the cards shown, children with intellectual disabilities mainly gave the following answer options: no answer or an absurd interpretation; misinterpretation. In normatively developing children, responses of a general nature were mainly noted, which can be attributed to a variety of situations of nonverbal.

When comparing the groups after psychological exposure, significant differences were found in comparison with the assessments before psychological exposure in all parameters. Children with intellectual disabilities received significantly higher scores in recognising and using gestures in various situations. Differences arose between the groups both in the cognitive and emotional-personal components and in the behavioural component. Corresponding differences were found in the group of children with a normative level of intellectual development. The data obtained are presented in Table 4

The findings confirm the earlier conclusion that the conducted program is highly effective in the development of non-verbal communication in children with intellectual disabilities. This is also confirmed by the high possibilities for correcting various aspects of non-verbal behaviour both in the group of children with intellectual disabilities and in the group of children with a normative level of development.

The study assessed children's non-verbal communication abilities based on expert assessments of teachers and parents. Expert assessments were carried out using questionnaires, the data on which were analysed and summarised using factor analysis to form generalised assessments of various parameters. A comparison was made between groups of children with intellectual disabilities and normatively developing children according to these parameters.

According to the results of expert assessments of parents, it was found that parents of children with intellectual disabilities and parents of children with a normative level of development have similar assessments of the communicative orientation, they

Table 4: Differences between Groups of Children with Intellectual Disabilities and the Normative Level of Intellectual Development in Terms of the Ability to Recognise and Understand Gestures after Psychological Impact

\begin{tabular}{|c|c|c|c|}
\hline Comparison parameter & 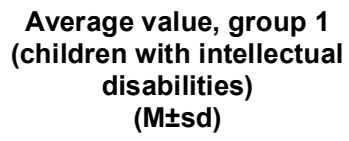 & 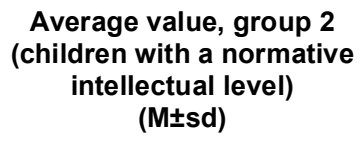 & $\begin{array}{l}\text { Significance level of } \\
\text { differences }(p)\end{array}$ \\
\hline Emotional-personal component & $3.11 \pm 10.87^{*}$ & $3.99 \pm 0.03$ & $<0.01$ \\
\hline Cognitive component & $6.84 \pm 0.08^{*}$ & $7.46 \pm 0.66$ & $<0.01$ \\
\hline Understanding of spatial relations & $3.16 \pm 0.06^{*}$ & $3.93 \pm 0.25$ & $<0.01$ \\
\hline Behavioural component & $3.17 \pm 0.05^{\star}$ & $3.99 \pm 0.08$ & $<0.01$ \\
\hline
\end{tabular}

Note: * - statistically significant differences were found for children from this group in comparison with the assessments for this parameter before psychological impact. 
Table 5: Differences between Groups of Normatively Developing Children and Children with Intellectual Disabilities According to Expert Assessments of Parents of Non-Verbal Communication Abilities before Psychological Impact

\begin{tabular}{|c|c|c|c|}
\hline Comparison parameter & 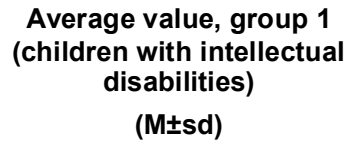 & 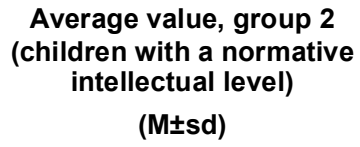 & $\begin{array}{c}\text { Significance level of } \\
\text { differences }(p)\end{array}$ \\
\hline Communicative focus & $2.9 \pm 9.87$ & $3.11 \pm 1.14$ & $>0.05$ \\
\hline Needs for communication & $3.9 \pm 0.02$ & $3.56 \pm 1.26$ & $>0.05$ \\
\hline Parents' directivity & $2.69 \pm 0.03$ & $2.80 \pm 0.88$ & $>0.05$ \\
\hline Intra-family interaction & $2.1 \pm 0.01$ & $2.96 \pm 1.56$ & $<0.01$ \\
\hline
\end{tabular}

have an equally expressed need for communication. The obtained differences are presented in Table $\mathbf{5}$. Parents of children of both groups are equally directive in the upbringing of children. At the same time, significant differences were found in the level of family interaction. Parents of children with intellectual disabilities are less focused on communicating with a child, spending leisure time with him, pay less attention to teaching their child communication skills.

It can be concluded that children with communication disorders receive less experience of interaction in the social environment, in the parental family, which they need to overcome existing communication disorders [2]. At the same time, given the absence of differences in communicative orientation, the need for communication with parents, a lower level of intrafamily interaction in families of children with intellectual disabilities may indicate frustration of the needs of the social level, which creates a risk of disruption in the functioning of a family.

According to the results of expert assessments after the program of psychological influence, a significant dynamics of the level of intrafamily interaction in the families of children with intellectual disabilities was established. The data are presented in Table 6. There are several reasons for this. On the one hand, as it was shown earlier, children have increased ability to communicate, which contributed to their own activity in communication, which affected relationships with parents. On the other hand, the parents themselves, in the course of observing the child's changes and communicating with a psychologist in the process of research and conducting a program of psychological influence, realised the need to communicate with a child to help him in establishing contacts with peers. Thus, it can be concluded that the program tested in this study is not only effective for the development of communication skills in children with intellectual disabilities but also contributes to the harmonisation of family relationships, which is especially important for optimising the social development of a child. The program of psychological influence helps to harmonise this environment so that a child can further develop in it as in a natural one, without the constant support of specialists.

Expert assessments of parents of children with a normative level of intellectual development did not show significant dynamics, but it should be noted that

Table 6: Differences between Groups of Children with Intellectual Disabilities and a Normative Level of Development According to Expert Assessments of Parents of Non-Verbal Communication Abilities after Psychological Influence

\begin{tabular}{|c|c|c|c|}
\hline Comparison parameter & 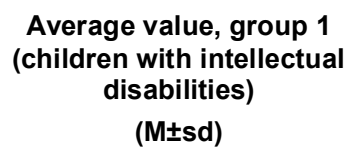 & 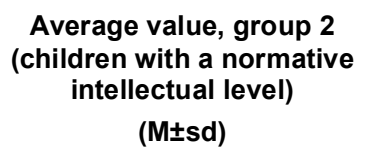 & $\begin{array}{c}\text { Significance level of } \\
\text { differences }(p)\end{array}$ \\
\hline Communicative focus & $3.06 \pm 10.87$ & $3.36 \pm 0.68$ & $<0.01$ \\
\hline Needs for communication & $3.79 \pm 0.08$ & $3.62 \pm 0.95$ & $>0.05$ \\
\hline Parents' directivity & $2.81 \pm 0.06$ & $2.90 \pm 0.79$ & $>0.05$ \\
\hline Intra-family interaction & $2.42 \pm 0.05^{\star}$ & $3.00 \pm 1.37$ & $<0.01$ \\
\hline
\end{tabular}

Note: * - statistically significant differences were found for children from this group in comparison with the assessments for this parameter before psychological impact. 
Table 7: Differences between Groups of Children with Intellectual Disabilities and the Normative Level of Intellectual Development According to Expert Assessments by Teachers of Non-Verbal Communication Abilities before Psychological Impact

\begin{tabular}{|c|c|c|c|}
\hline Comparison parameter & $\begin{array}{c}\text { Average value, group } 1 \\
\text { (children with intellectual } \\
\text { disabilities) } \\
\text { (M士sd) }\end{array}$ & 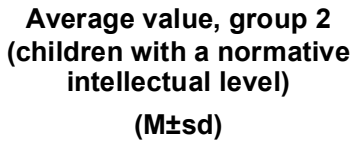 & $\begin{array}{l}\text { Significance level of } \\
\text { differences }(p)\end{array}$ \\
\hline Cognitive component & $2.7 \pm 7.87$ & $2.79 \pm 1.21$ & $>0.05$ \\
\hline Emotional-personal component & $3.41 \pm 0.05$ & $3.48 \pm 1.21$ & $>0.05$ \\
\hline Egocentrism & $3.62 \pm 0.13$ & $3.16 \pm 1.04$ & $<0.01$ \\
\hline
\end{tabular}

they were at a high level even before the program of psychological influence.

According to the results of an expert assessment by teachers of children's abilities for non-verbal communication, a significantly higher level of egocentrism was found in children with intellectual disabilities. The results of the assessment are shown in Table 7. The assessments of the cognitive and emotional-personal components differ little in different groups. The found differences in egocentrism in different groups of children can be explained by the previously found differences in the level of intrafamily interaction in the expert assessments of parents. As a rule, children with attention-deficit on the part of their parents find a decrease in the ability to look at what is happening from the perspective of another person, to understand other people, and to establish communicative contact with them. Egocentrism is an age-related normative property of the thinking of children, but at the same time, it can create difficulties for a child to adapt to other social systems outside the family, as this requires each time to see the situation from different angles.

According to the results of the expert assessment by teachers after the program of psychological influence, the absence of statistically significant dynamics in the assessments of egocentrism was found, but at the same time, the smoothing of differences in these assessments between the group of children with a normative level of intelligence and the group of children with developmental disorders was found. The results are shown in Table 8. Taking into account the age normality of children's egocentrism, equalising this assessment with the assessments of normatively developing children can be considered as a significant result of the program. It should be noted that there was a significant dynamic in teachers' assessments of the emotional-personal component. Comparison of teachers' expert assessments of children's non-verbal communication abilities indicates the effectiveness of the program in this area as well.

Based on the results of the conducted comparisons, it can be concluded that the performed program of psychological influence is highly effective. As its main advantages, it should be emphasised the multidimensionality of its significance in terms of the personal development of children. According to the data obtained and described above, the program contributes to the development of various components of non-verbal communication in children - the development of its cognitive, emotional-personal, behavioural components. At the same time, the effectiveness of the program in harmonising relations

Table 8: Differences between Groups of Children with Intellectual Disabilities and a Normative Level of Development According to Expert Assessments by Teachers of Non-Verbal Communication Abilities after Psychological Influence

\begin{tabular}{|c|c|c|c|}
\hline Comparison parameter & 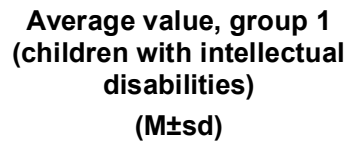 & 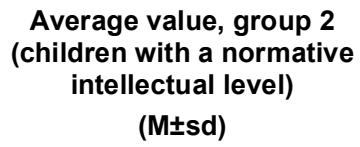 & $\begin{array}{c}\text { Significance level of } \\
\text { differences }(p)\end{array}$ \\
\hline Cognitive component & $2.89 \pm 9.87$ & $3.04 \pm 0.86$ & $>0.05$ \\
\hline Emotional-personal component & $3.36 \pm 1.08^{*}$ & $3.62 \pm 0.59^{*}$ & $<0.01$ \\
\hline Egocentrism & $3.55 \pm 1.16$ & $3.41 \pm 0.66$ & $>0,05$ \\
\hline
\end{tabular}

Note: * - statistically significant differences were found for children from this group in comparison with the assessments for this parameter before psychological impact. 
between children and parents was confirmed. From the data obtained, it follows that the ongoing program helps to fill the communication deficit in families. This aspect of the effectiveness of the program seems to be especially important since it is the harmonisation of the natural family parental environment that is the key to the normative development of the child with both the normative level of intelligence and intellectual disabilities. The program contributes to the correction of children's egocentrism, which is especially important for the adaptation of a child in society, including in the children's team. This aspect is of particular importance for children of primary school age since social maladjustment at this age can lead to the impaired learning activity and, thus, the frustration of the leading need, the implementation of which is already difficult in children with intellectual disabilities.

It should be emphasised that the data obtained on the current state and dynamics of various indicators indicate the correction potential not only of the program itself but also of children with developmental disorders. This is especially important because children with intellectual disabilities tend to receive less attention as less capable of change. The data obtained indicate the opposite. The conclusions drawn testify not only to the effectiveness but also to the relevance of the ongoing program of psychological influence.

\section{DISCUSSION}

There are various types of non-verbal development for children with intellectual disabilities. Drama therapy and rehabilitation group practice thematic design is based on the richness and variety of styling materials that are reflected in the activities. According to the research results, the selection of materials and the thematic design of the classes correlated with the presentation of the participants' children in the classroom. For example, in the "Vampire and Companion" thematic activity, invented by the study authors, it was new for the children, and they were interested in what opened up opportunities for communication and cooperation. Therefore, in this session, children-participants performed very well in both communication and cooperation, with significant improvements in non-verbal comprehension and expression. This was also observed by employees who reported $(45 \%)$ instances of communication and collaboration in sessions. Their social skills have also improved. Employees reported (63\%) observed interaction situations. Throughout the process of drama therapy, the participating children showed a strong interest in participation that was voluntary, spontaneous and enjoyable. Staff reported a $100 \%$ satisfaction rate for the children involved. In addition, the complexity of classroom activities affects the spontaneous participation of children. If a task were too difficult, which was completely "out of reach" for the participating children, their enthusiasm and participation would be limited. It is fair to say that by creating a supportive environment, children get the opportunity to see their capabilities. It can be said that the activities in this program were consistent with the level of understanding of the children and they were able to connect with them, as evidenced by the observed participation rate of $96 \%$. The choice of materials was based on the principle of simplicity and variety, and mainly on specific materials with which children were familiar. Simple and familiar materials can prevent stress and discomfort in children due to lack of experience with materials. A varied selection of materials and teaching children to understand art materials during the course of the class contributes to the development of visual language. As part of the "desert island" thematic event, children swam to the island, planted flowers and trees there, created cute animals out of clay, built houses using small stones and colourful building blocks. Finally, the uninhabited island became an oasis for life. Some of the participating children with good language skills expressed naturally and spoke a lot in this exercise. Other children participated non-verbally, using familiar materials such as watercolours, blocks, ropes, and stones to relieve kinaesthesia and allow energy to flow with emotion and imagination [16]. In addition to this research, it is important to note that such methods of developing children with intellectual disabilities can become much more effective. By breaking down the components of creative therapy into verbal and nonverbal communication tools, one can understand how to increase the benefits of such programs. This study examines the features of non-verbal communication in children with developmental delay.

Another interesting study showed the possibilities of communication in one family of children with normal development and intellectual disabilities. It was noted that variables that provide more descriptive information about sibling characteristics and relationships, as well as parenting and family factors, are arguably more important in explaining the variability in adaptation outcomes among children [17]. However, in this study, the quality of the relationship between siblings was strongly associated with the adaptation of children 
based on the reports of children and mothers and children's drawings. In particular, in line with previous research, increased negative aspects of relationships (e.g., rivalry, power, conflict) explain significant differences in externalising behaviour among children. Regardless of group membership, previous studies of children showed that sibling conflicts and children's behaviour problems were positively associated. In contrast to previous findings on the contribution of negative aspects of sibling relationships to increased internalising symptoms $[18,19]$, it was found that aspects of the relationship, related to problems of internalisation of children, included the presence of parents in their drawings and reports of children about rivalry (these are also related to each other, albeit with little effect). The effect of parental presence in children's drawings was consistent with the increased burden of caring for ID children. This can spill over into the sibling subsystem, leading to increased parental involvement in family relationships. The increased parental involvement shown in the figures may be motivated by parents who foresaw the importance of sibling relationships in the future when they could no longer manage the care of their ID child. In any case, the drawings suggest that parental influence is critical to sibling relationships and how ID siblings perceive and deal with a difficult situation. Negative aspects of relationships reported by mothers (avoidance behaviour) and children (conflict and competition) were negatively associated with prosocial behaviour in children. Mothers told that compassion in relationships was positively associated with prosocial behaviour. In addition, the measure of the proportion of sizes in the drawings of children was negatively associated with prosocial behaviour. The size and proximity of the figures in the family drawings provide information about aspects of family interaction and reflect the children's experience of relationships. A number of researchers have suggested that the size and position of the human figure in the drawing reflect the artists' perceptions of their social role, including feelings of inferiority in relation to the demands of the environment and a decrease in confidence in their social status. Other research supports the hypothesis that sibling relationships that provide support, communication, affection, and other positive qualities can improve prosocial competence development [20]. In essence, the quality of the sibling relationship is a form of social support associated with psychological adjustment [21]. Thus, sibling difficulties other than having a sibling with an ID are important for the adjustment of children. The structural-dynamic approach to modelling the phenomenological content of non-verbal communication in children with intellectual disabilities will further improve the differential diagnosis of mental disorders in accordance with the international multi-axis clinical classification. Further in-depth study of the various components of non-verbal communication during its development according to the dysontogenic type will have a great impact on the optimisation of the conditions for psychological influence and psychotherapy of children with intellectual disabilities.

\section{CONCLUSION}

After psychological influence, statistically, significant differences are found when studying the severity of egocentrism. Children with a normative level of intellectual development show a higher degree of egocentrism than a group of children of primary school age with mixed specific disorders of mental development, which indicates that students from this group, as a result of psychological influence, have become more attentive to themselves and their experiences.

Based on the analysis of parents' expert assessments, no significant differences were found in the development of non-verbal communication between all the studied groups of children. This is explained by the fact that parents tend to focus on subjective expectations in adapting the child to new social conditions in the presence of insufficient special knowledge in the field of medical psychology, which led to the initial setting of higher marks regardless of the clinical diagnosis.

\section{ACKNOWLEDGEMENTS}

None.

\section{ABBREVIATION}

ID = intellectual disability

$\mathrm{MD}=$ mental retardation

MSDD = mixed specific disorder of psychological development

\section{REFERENCES}

[1] Al-Yagon M. Perceived close relationships with parents, teachers, and peers: Predictors of social, emotional, and behavioral features in adolescents with LD or comorbid LD and ADHD. Journal of Learning Disabilities 2016; 49: 597615.

https://doi.org/10.1177/0022219415620569 
[2] Abramenkova VV. Childhood psychology in the context of the relationship of a child in the world. Psychology issues 2002; 1: 3-16.

[3] Vygotsky LS. Collected Works. In 6 volumes. V. 5. In TA. Vlasova (Ed). Moscow: Pedagogika, 1983.

[4] Bradley E, Hollins S. Books Beyond Words: Using Pictures to Communicate. Journal of Developmental Disabilities 2013; 19: 24-32.

[5] Solodiuk JC. Parent described pain responses in nonverbal children with intellectual disability. International Journal of Nursing Studies 2013; 50(8): 1033-1044. https://doi.org/10.1016/j.jjnurstu.2012.11.015

[6] Zaidman-Zait A, Yechezkiely M, Regev D. The quality of the relationship between typically developing children and their siblings with and without intellectual disability: Insights from children's drawings. Research in Developmental Disabilities 2020.

https://doi.org/10.1016/j.ridd.2019.103537

[7] Fenning RM, Baker JK, Baker BL, Crnic KA. Parent-child interaction over time in families of young children with borderline intellectual functioning. Journal of Family Psychology 2014; 28: 326-335.

https://doi.org/10.1037/a0036537

[8] Nienke PS, Robert D, Hubert K. Understanding of intentions in children with autism spectrum disorder and intellectual disability. Advances in Neurodevelopmental Disorders 2017; (1): 3-15.

https://doi.org/10.1007/s41252-017-0052-2

[9] Fink E, Begeer S, Peterson CC, Slaughter V, de Rosnay M. Friendlessness and theory of mind: A prospective longitudinal study. British Journal of Developmental Psychology 2015; 33: 1-17. https://doi.org/10.1111/bjdp.12060

[10] Barton-Hulsey A, Sevcik RA, Romski M. Narrative language and reading comprehension in students with mild intellectual disabilities 2017; 122(5): 392-408.

https://doi.org/10.1352/1944-7558-122.5.392

[11] Courbin P. On the non-verbal communication between mentally disabled children. International Journal of Rehabilitation Research 1980; 3(4): 543-544. https://doi.org/10.1097/00004356-198012000-00015

[12] Floyd FJ, Olsen DL. Family-peer linkages for children with intellectual disability and children with learning disabilities. Journal of Applied Developmental Psychology 2017; 52: 203211.

https://doi.org/10.1016/j.appdev.2017.08.001
[13] Cohen E, Houtrow A. Disability Is Not Delay: Precision Communication about Intellectual Disability. The Journal of Pediatrics 2019. https://doi.org/10.1016/j.jpeds.2018.12.040

[14] Lebedinskaya KS. Mental developmental disorders in childhood and adolescence. Moscow: Academic project, 2011.

[15] Kozlova EA, Ovchinnikova AA. Development and correction of the emotional-volitional sphere in children of primary school age with intellectual disabilities in the process of adapting to school. Perm: PPSU, 2014.

[16] Chen K, Wu J, Ma Y, Vomochilova J. Early intervention for children with intellectual and developmental disability using drama therapy techniques. Children and Youth Services Review, 2020. https://doi.org/10.1016/j.childyouth.2019.104689

[17] Neece CL, Blacher J, Baker BL. Impact on siblings of children with intellectual disability: The role of child behavior problems. American Journal on Intellectual and Developmental Disabilities 2010; 115(4): 291-306. https://doi.org/10.1352/1944-7558-115.4.291

[18] Campione-Barr N, Greer KB, Kruse A. Differential associations between domains of sibling conflict and adolescent emotional adjustment. Child Development 2013; 84(3): 938-954. https://doi.org/10.1111/cdev.12022

[19] Pollard CA, Barry CM, Freedman BH, Kotchick BA. Relationship quality as a moderator of anxiety in siblings of children diagnosed with autism spectrum disorders or Down syndrome. Journal of Child and Family Studies 2013; 22(5): 647-657. https://doi.org/10.1007/s10826-012-9618-9

[20] Harper JM, Padilla-Walker LM, Jensen AC. Do siblings matter independent of both parents and friends? Sympathy as a mediator between sibling relationship quality and adolescent outcomes. Journal of Research on Adolescence 2016; 26(1): 101-114.

https://doi.org/10.1111/jora.12174

[21] Buist KL, Dekovich M, Prinzie P. Sibling relationship quality and psychopathology of children and adolescents: A metaanalysis. Clinical Psychology Review 2013; 33(1): 97-106. https://doi.org/10.1016/j.cpr.2012.10.007

Received on 30-10-2020

Accepted on 14-11-2020

Published on 27-11-2020

DOI: https://doi.org/10.6000/2292-2598.2020.08.04.5

(C) 2020 Oksana V. Zashchirinskaia; Licensee Lifescience Global.

This is an open access article licensed under the terms of the Creative Commons Attribution Non-Commercial License (http://creativecommons.org/licenses/by-nc/3.0/) which permits unrestricted, non-commercial use, distribution and reproduction in any medium, provided the work is properly cited. 